\title{
Evaluation of multilayer film stability by Raman spectroscopy after gamma-irradiation sterilization process
}

\author{
Fanny Gaston ${ }^{\mathrm{a}, \mathrm{b}, \mathrm{d}, *}$, Nathalie Dupuy ${ }^{\mathrm{a}}$, Sylvain R.A. Marque ${ }^{\mathrm{b}, \mathrm{c}}$, Samuel Dorey ${ }^{\mathrm{d}, *}$ \\ a Aix Marseille Univ., Univ. Avignon, CNRS, IRD, IMBE, Marseille, France \\ ${ }^{\mathrm{b}}$ Aix Marseille Univ., CNRS, ICR, Case 551, 13397 Marseille, France \\ ${ }^{\mathrm{c}}$ Vorozhtsov Novosibirsk Institute of Organic Chemistry Office 312, 9 Prospect Academican Laurentiev, 630090 Novosibirsk, Russia \\ d Sartorius Stedim FMT S.A.S, Z.I. Les Paluds, Avenue de Jouques CS91051, 13781 Aubagne Cedex, France
}

Keywords:

Raman spectroscopy

Gamma-irradiation

Multilayer polymer film

Curve resolution analysis

\begin{abstract}
Polymers such as polyethylene (PE) and ethylene vinyl alcohol (EVOH) are primary constituents of single use plastic systems in the biopharmaceutical and biotechnology industries. These devices are sterilized by gamma-irradiation prior to be used, the usual dose being between 25 and $45 \mathrm{kGy}$. Optical spectroscopies are of great interest for chemical analysis and are used to obtain information on the composition of materials such as polymers. Raman spectroscopy provides information on the fundamental vibrations of molecules, using excitation in the visible wavelength range. The purpose of this study is to unveil the impact of gamma-sterilization on polymers in industry-like experimental conditions. Cross-sections of films are analyzed before and after sterilization using different radiation doses: their compositions and chemical evolution of the material are examined using micro-Raman spectroscopy. As the chemical composition of the layers is complex, due to the presence of additive compounds, there is considerable overlap between the spectral data. In this case, the use of spectral curve resolution chemometric methods is unique for unravelling the complex identification of the layers and to study the degree of chemical modifications.
\end{abstract}

\section{Introduction}

The preparation, storage, mixing, freezing, transportation, formulation, and filling of biopharmaceutical solutions are performed in sterile single-use plastic bags. The sterility is achieved through gamma-irradiation, which generates material modifications, as reported in the literature [1]. The integrity and security of packages rely on the appropriate flexibility and barrier property of polymeric materials such as polyethylene and polyethylene-co-vinyl alcohol, respectively [2]. Gamma-sterilization of single-use systems initiates chemical reactions inside the plastic material, leading to either an increase or a decrease in the molecular weights of polymers $[3,4]$. In our work, we focus on the effects of gamma-irradiation on the solid state of a multilayer polymer film (PE/EVOH/PE), made of polyethylene $(\mathrm{PE})$ - a polymer with interesting water barrier properties and mechanical properties [5] - and ethylene vinyl alcohol (EVOH) - remarkable for its barrier properties to $\mathrm{CO}_{2}$ and $\mathrm{O}_{2}$ molecules [2].

Gamma-sterilization of these systems affords complex modifications inside the material, leading to the modifications of additive compounds or to the damage of the polymers themselves [6-8]. Irradiation of polymeric materials has been proven to initiate radical chemical reactions inside the polymeric material [9] leading to either an increase or a decrease in the polymer molecular weight [3,4]. The effects of gamma-irradiation on polymers are well known [6-8,10-12], whereas the effects of gamma-irradiation on multilayer films have been little investigated [2]. The Scheme 1 displays the generation of first and second generation radicals upon gamma-irradiation.

Nevertheless, we expect that the initial reaction will be the same in multilayer film than in PE and EVOH monolayer film. Moreover, very similar chemistry is also expected for the decay of first and second generation of radical species as cross-linking and scission (bond breaking) induce modifications to the matrix environment by introducing connections or branching in the polymer chains (decrease in $-\mathrm{CH}_{2}-$ groups) and breaking polymer chains (increase in $-\mathrm{CH}_{3}$ end groups), respectively. 


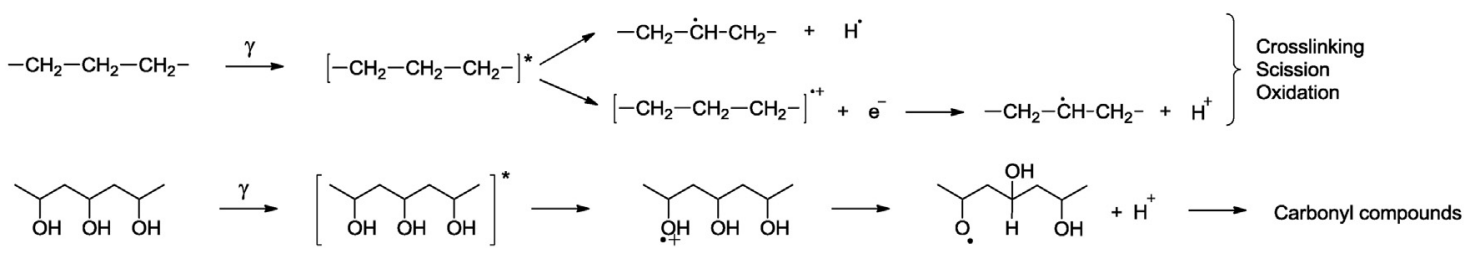

Scheme 1. First and second generation of radicals upon gamma-irradiation of PE and EVOH.

Modifications in polymers can be observed by spectroscopic methods and especially Raman spectroscopy, which is a powerful optical technique spectroscopy with several advantages to investigate the molecular deformations behavior of opaque and thick polymeric material samples [13-20]. Raman spectroscopy provides a complementary approach to infrared absorption spectroscopy for which transparent and very thin films are required. Micro-Raman spectroscopy makes possible to reach the intercalated layer with a better resolution than $\mu$-ATR (Attenuated Total Reflectance) infrared spectroscopy, and offers the possibility to observe the vibrations of the $\mathrm{C}-\mathrm{C}$ bond skeleton in the main chains [16,21,22], with a better signal than in FTIR. As the $\mathrm{C}-\mathrm{C}$ bond stretching vibration is strongly Raman active, microenvironments of the polymer chains are probed by the wavelength shifts [23-25]. Degradation of polymers under gamma-irradiation investigated by Raman spectroscopy is well known [26,27]. However, the degradation of multilayer films has been little investigated and even less using chemometric methods $[28,29]$. Thus it is possible to perform a mapping of three layers film using Raman spectroscopy and to identify the modification in each layer with the help of chemometrics

Gamma-irradiation on multilayer films leads to Raman spectra variations, which are highlighted using chemometric methods. The chemometric tool used in this study and applied to Raman spectra is a curve resolution method named SIMPLISMA (SIMPLe-to-use Interactive Self Modeling Analysis). The SIMPLISMA approach [30] is used to define chemical species rising during gamma-irradiation and to monitor their evolution. Retrieving reconstructed Raman spectra may afford identification of the compounds present in the polymer film before and after irradiation. The concentration profiles give relative quantitative information highlighting the variation in polymer modification after the different gammadoses. The classical gamma-irradiation dose range used in biopharmaceutical industries is 25-45 kGy [31]. The gammairradiation doses investigated in this study are up to $270 \mathrm{kGy}$ in order to increase and exaggerate the gamma-irradiation effect and thus to better emphasize and to investigate the gamma-ray induced modifications. Briefly, the most significant changes are observed on the stabilizer and on the tie layer, which corresponds to the interface between the EVOH layer and the PE layer and which allows bonding between these two layers.

\section{Materials and methods}

\subsection{PE-film}

The structure of the multilayer PE-film, provided by Sartorius Stedim FMT (Aubagne, France), is depicted in Fig. 1. This film was prepared by extrusion.

The different layers in this film contain additive compounds including antioxidants (especially phenol, phosphite [32-34], and other aromatic compounds), antiblocking agents and plasticizers. The corresponding molecules cannot be disclosed here due to protection by confidentiality agreement. The EVOH and PE layers contain additive compounds for their stabilization during the manufacturing process and during their shelf life. In this article, we

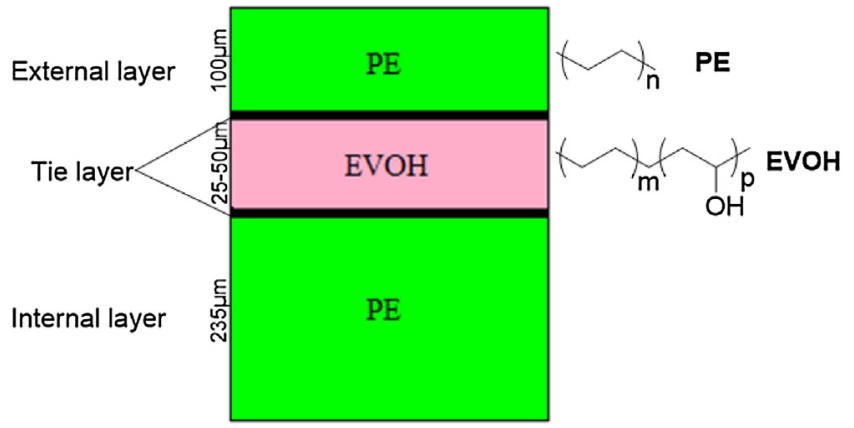

Fig. 1. Molecular structure of PE-film. The internal layer is the side of the film in contact with the solution when the bag is filled. The external layer is the side of the film in contact with air. The tie layer is used to glue PE and EVOH layers together.

distinguish the PE or EVOH polymer alone and the PE or EVOH resin, which is the mixture of the $\mathrm{PE}$ or $\mathrm{EVOH}$ polymer plus the additives. The different layers are necessarily made of the resin. The two PE layers which constitute the internal and external layers of PE-film are both LDPE and differ in their branching degree. The internal layer is the side of the film in contact with the solution when the bag is filled with biological solution, and the external layer is the side of the film in contact with air. There is a tie layer between $\mathrm{EVOH}$ and the internal and external PE layers (bold lines in Fig. 1). This tie layer is made of maleic anhydride-PE modified. The anhydride function grafted on PE reacts with the EVOH hydroxyl group to generate an ester function that ties the two layers together (Scheme 2). The proportion of maleic anhydride is $<1 \%$ in the tie layer and should not be detectable by Raman spectroscopy.

The Raman analyses were performed on four batches of PE-film, to check if there are changes between the different manufacturing batches. After processing of data, there is no difference between each batch, thus for the sake of simplicity, only results of one batch are discussed hereafter.

\subsection{Gamma irradiation}

Sheets of film (thickness of about $400 \mu \mathrm{m}$ ) were packed and wrapped in specific packaging (PE) and irradiated at room temperature in a ${ }^{60} \mathrm{Co}$ gamma-source. The ${ }^{60} \mathrm{Co}$ gamma-source provides a dose rate of $8-13 \mathrm{kGy} / \mathrm{h}$, as given by the Synergy Health company (Marseille, France), affording doses at $30( \pm 1), 50( \pm 1)$, $115( \pm 2)$ and $270( \pm 5) \mathrm{kGy}$. A sterilization cycle corresponds approximately to $25 \mathrm{kGy}$. To obtain the targeted dose, it is necessary to perform several sterilization cycles, including noncontrolled waiting time between cycles under non-controlled storage conditions. Two irradiation campaigns were performed with four batches each to check whether the irradiation has an impact on our results. The Raman spectroscopy analyses of the film samples obtained during the two campaigns of irradiation lead to similar results which are thus not affected by these non-controlled conditions. The samples were analyzed by Raman about 10 days after gamma-irradiation and the recording of the large number of 


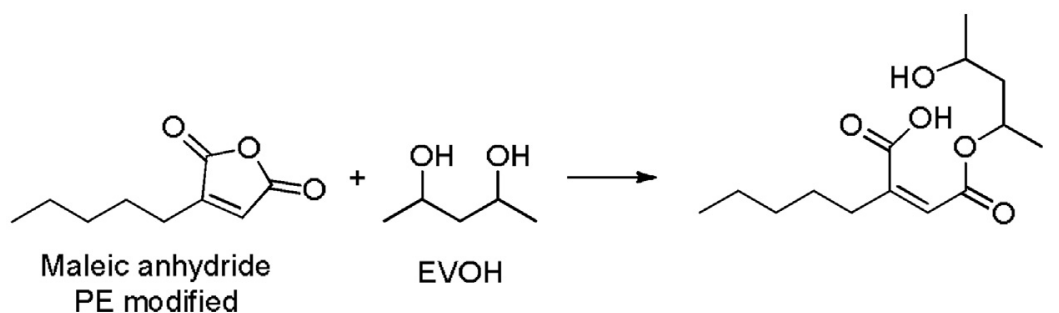

Scheme 2. Reaction at the level of the tie layer.

spectra (about 300 spectra on average) lasted several days as one mapping needs around four hours.

\subsection{Raman spectroscopy}

Spectra were collected with an Almega (Thermo-Fisher Scientific Nicolet, Omnic 8.3 software) Raman spectrometer equipped with a Nd: YVO4 diode-pumped solid-state (DPSS) laser $(532 \mathrm{~nm})$, through an Olympus high stability BX 51 microscope coupled in confocal. The detector was a charge coupled device (CCD). A $100 \mu \mathrm{m}$ slit provided sufficient resolution, which is exactly $2 \mathrm{~cm}^{-1}$. Spectra were recorded with two expositions of $10 \mathrm{~s}$ each, at $150 \mathrm{~mW}$ laser power in the spectral range $90-4245 \mathrm{~cm}^{-1}$. The backscattered radiation was collected with the same microscope objective: Olympus objective of $\times 20$. The spot size of the laser focused by the $\times 20$ (NA 0.4 ) objective at the sample was estimated to be approximately $2 \mu \mathrm{m}$ in diameter. The spectrometer calibration was checked using the Raman line of silicon at $520.7 \mathrm{~cm}^{-1}$. A color camera was used to feed a signal to a video monitor, and thus provided an optical view of the sample. The microscope stage was XY motorized and computer controlled for spot-by-spot scanner imaging. Raman data sets were collected by point-by-point scanning, with a scanning step of $10 \mu \mathrm{m}$. Synchronization of stage, movement, data collection and conventional data processing for mapping was performed with the Omnic 8.3 software. Spectra were collected and then analyzed using chemometric methods.

The cross sections of sample were prepared with a surgical scalpel to be subsequently analyzed by Raman spectroscopic mapping.

Five mappings were performed: one for each irradiation dose. $408,415,239,151$ and 362 spectra were recorded for irradiation at 0 (not sterilized), 30, 50, 115 and $270 \mathrm{kGy}$, respectively. The step size between two analytical points was $10 \mu \mathrm{m}$. The dimensions of the manually-drawn maps varied between samples implying then a different number of spectra among the mappings.

\subsection{Curve resolution method}

The method used for self-modeling mixture analysis is the SIMPLISMA method described in the literature [29,35-39]. This interactive method is used for self-modeling mixture analysis by resolving mixture data into pure component spectra and concentration profiles without the help of prior information about the mixture. In the case of plastics it is always a mixture of polymer and additives (mineral and organic). SIMPLISMA will consider as "pure" either a mono-material or a mixture which evolve in the same way during irradiation. When overlapping spectral features

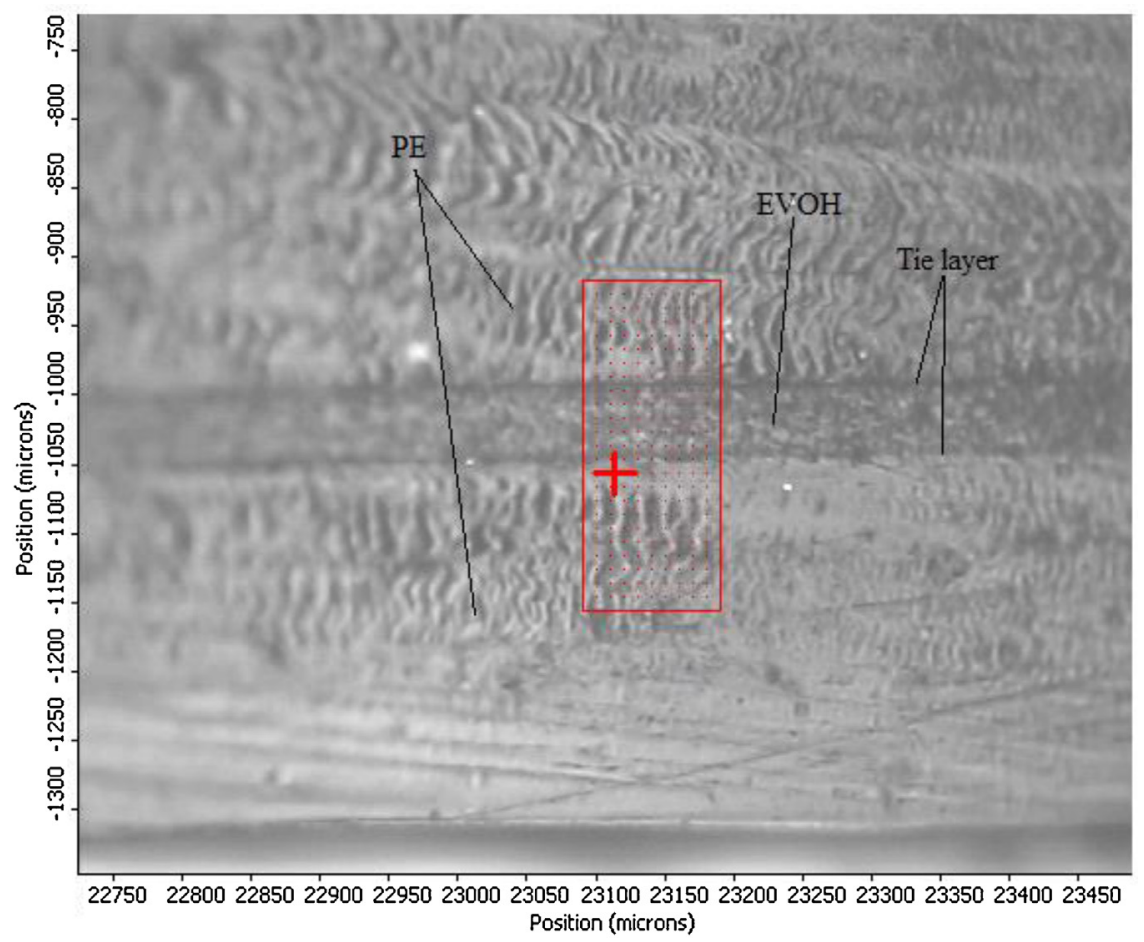

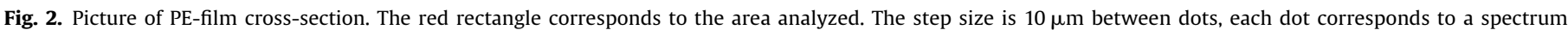
acquisition. (For interpretation of the references to colour in this figure legend, the reader is referred to the web version of this article.) 
are present in spectroscopic data, this tool is unable to resolve broad spectral components and separate spectral absorption bands characterizing one component. Its concept is based on the determination of pure variables (e.g., a wavelength or a wavenumber in spectroscopic terms) that have received the contributions from only one component and an optimization using leastsquare method [40].

In order to obtain the proper resolution of the mixture data, user interaction is required to deal properly with features such as noise, peak shift, and instrument drift [41]. Some applications of SIMPLISMA have already been reported in the literature, e.g., on Fourier transform Raman spectra for the time resolved activation of hydrogen peroxide by a nitrile [30], analysis of oil petroleum [42], FT-IR microscopy spectra of a polymer laminate, and pyrolysis mass spectra of biomaterials (feedstock) $[35,40]$. The fitting of the SIMPLISMA results is calculated using the Relative Residual Sum of Squares (RRSSQ), square sum between the calculated and the original spectra. The SIMPLISMA data treatments were performed with Matlab 7.14 software. The up-ward shift of the baseline due to the fluorescence is corrected with Savitzky Golay derivative preprocessing.

\section{Results and discussion}

\subsection{Characterization of PE-film by Raman spectroscopy}

The optical picture of the PE-film cross-section, which corresponds to the film irradiated at $30 \mathrm{kGy}$ (Fig. 2), shows the $\mathrm{PE} / \mathrm{EVOH} / \mathrm{PE}$ layer structure.

The Raman assignments for the three layers and tie layer are listed in Table 1, according to the literature [13,21,23,25,43-48]. In Table 1 , most of peaks are assigned to skeletal $\mathrm{C}-\mathrm{C}$ bond of polymers, as this bond stretching vibration is strongly Raman active [22]. The spectra for the layers at $0 \mathrm{kGy}$, are displayed in Fig. 3.

Fig. 3a) displays the Raman spectrum for the non-sterilized internal PE layer of films and the Raman spectrum of the nonsterilized external PE layer of films. Fig. 3b) shows the Raman spectrum for the non-sterilized EVOH layer. These spectra show the bands characterizing bond vibrations in the PE and $\mathrm{EVOH}$ polymers.

Internal and external PE layer differ in their branching (they are manufactured using different resins) and in their slightly different additive compound compositions. Peaks displayed in Fig. 3a) are all assigned to PE signal (Table 1) whatever it is internal or external layer. However, the differences observed between signals of internal and external PE layers (see insert Fig. 3a)) are not significant enough to be pinpointed even by ACP due to the high variance induced by the presence of $\mathrm{EVOH}$ (see Fig. 1 SI) and do not deserve more discussion presently. The EVOH (polyethylene-covinyl alcohol) and PE (polyethylene) have in common all the PE bands and spectra display therefore some similarities, as they contain peaks typical of alkanes. Except for peaks at $3051 \mathrm{~cm}^{-1}$, $1597 \mathrm{~cm}^{-1}, 1028 \mathrm{~cm}^{-1}, 995 \mathrm{~cm}^{-1}$, other peaks are ascribed to PE and the peak at $3373 \mathrm{~cm}^{-1}$ is typical of hydroxyl moiety and ascribed to EVOH (Table 1). Four peaks in the EVOH layer spectrum at $3051 \mathrm{~cm}^{-1}, 1597 \mathrm{~cm}^{-1}, 1028 \mathrm{~cm}^{-1}$ and $995 \mathrm{~cm}^{-1}$ should then correspond to the additive compounds. Other peaks of additives are also common with those of PE and EVOH and cannot be used as material discrimination in that case.

The large number of data and the weak intensity of changes concerning the peaks induced by the gamma irradiation could not give obvious results and conclusion with manual calculations leading to use a curve resolution method (SIMPLISMA method).

\subsection{SIMPLISMA}

To assess the variability in polymer fingerprints induced by gamma-irradiation, the SIMPLISMA treatment was then applied to the 1575 spectra recorded for non-irradiated and irradiated samples. Three reconstructed spectra of main species are then obtained and associated to: one for the PE layer (Fig. 4a)), one for the EVOH layer (Fig. 4b)), and another one for the additive compounds contained in the EVOH layer (Fig. 4c)). Sum of spectra corresponding to Fig. $4 \mathrm{~b}$ ) and c) correspond to the spectrum displayed on Fig. $3 \mathrm{~b}$ ). The spectra reconstructed and associated to the PE and EVOH layers show wavenumbers identical to those listed in the Table 1. It shows thus that the PE and EVOH underwent no detectable modification after the different gamma irradiation doses. The SIMPLISMA treatment allows us obtaining in parallel the spectra of the main additive compounds in the EVOH layer confirming peaks deduced from those not assessed to the EVOH in Fig. 3b).

Three reconstructed signals are enough to account for the variation in the data set (RRSSQ is $<0.05$ ). Processing data does not reveal any difference between the external PE layer and the

Table 1

Raman assignments of bands for spectra of each layer of PE-film.

\begin{tabular}{|c|c|c|c|c|c|c|c|}
\hline Wavenumber $\left(\mathrm{cm}^{-1}\right)$ & functional groups & Type of vibration & PE & $\mathrm{EVOH}$ & $\begin{array}{l}\text { Additive } \\
\text { compounds }\end{array}$ & $\begin{array}{l}\text { Tie } \\
\text { layer }\end{array}$ & \\
\hline 3400 & $v-\mathrm{OH}$ & Stretching & & $\mathrm{X}$ & & & [48] \\
\hline $3050-3060$ & $\nu-\mathrm{CH}=\mathrm{CH}-$ & Stretching in aromatic compounds & & & $\mathrm{X}$ & & {$[43,47]$} \\
\hline 3010 & $\nu-\mathrm{CH}=\mathrm{CH}-$ & Stretching in non-aromatic compounds & & & & $\mathrm{X}$ & [43] \\
\hline 2907 & $\nu-\mathrm{CH}_{2}-$ & & & $\mathrm{X}$ & & & [49] \\
\hline $2876-2878$ & $\nu-\mathrm{CH}_{2}-$ & Antisymmetric stretching & $\mathrm{X}$ & $\mathrm{X}$ & $\mathrm{X}$ & $\mathrm{X}$ & {$[13,23,43]$} \\
\hline $2840-2851$ & $\nu-\mathrm{CH}_{2}-$ & Symmetric stretching & $\mathrm{X}$ & $\mathrm{X}$ & $\mathrm{X}$ & $\mathrm{X}$ & {$[13,23,43]$} \\
\hline 2721 & $\nu-\mathrm{CH}_{3}$ terminal & Stretching & $\mathrm{X}$ & $\mathrm{X}$ & $\mathrm{X}$ & & [47] \\
\hline $1595-1601$ & $\begin{array}{l}\nu-\mathrm{C}=\mathrm{C} \text { conjugated or benzene } \\
\text { rings }\end{array}$ & Stretching & & & $\mathrm{X}$ & $\mathrm{X}$ & [47] \\
\hline 1460 & $\delta-\mathrm{CH}_{2}-$ & Rocking (Antisymmetric in plane deformation) & $\mathrm{X}$ & & $\mathrm{X}^{\mathrm{a}}$ & $\mathrm{X}$ & {$[21,43,44,46]$} \\
\hline $1438-1412$ & $\delta-\mathrm{CH}_{2}-$ & Bending (Symmetric in plane deformation) & $\mathrm{X}$ & $\mathrm{X}$ & $\mathrm{X}^{\mathrm{a}}$ & & {$[21,23,43-46]$} \\
\hline 1365 & $\omega-\mathrm{CH}_{2}-$ & Wagging (Symmetric out of plane deformation) & $\mathrm{X}$ & $\mathrm{X}$ & $\mathrm{X}^{\mathrm{a}}$ & & {$[23,43,44,46]$} \\
\hline 1292 & $\tau-\left(\mathrm{CH}_{2}\right)_{\mathrm{n}}-$ & $\begin{array}{l}\text { Twisting (Antisymmetric out of plane } \\
\text { deformation) }\end{array}$ & $\mathrm{X}$ & $\mathrm{X}$ & $\mathrm{X}^{\mathrm{a}}$ & $\mathrm{X}$ & $\begin{array}{l}{[21,23,43,45-} \\
47]\end{array}$ \\
\hline 1167 & $\delta-\mathrm{CH}_{2}-$ & Rocking (Antisymmetric in plane deformation) & $\mathrm{X}$ & & $\mathrm{X}^{\mathrm{a}}$ & & {$[21,23,43,46]$} \\
\hline 1125 & $v-\mathrm{CH}_{2}-\mathrm{CH}_{2}-$ & Symmetric stretching & $\mathrm{X}$ & $\mathrm{X}$ & $\mathrm{X}^{\mathrm{a}}$ & $\mathrm{X}$ & {$[21,23,25,43]$} \\
\hline 1060 & $v-\mathrm{CH}_{2}-\mathrm{CH}_{2}-$ & Asymmetric stretching backbone stretching & $\mathrm{X}$ & $\mathrm{X}$ & $\mathrm{X}^{\mathrm{a}}$ & $\mathrm{X}$ & {$[21,23,43]$} \\
\hline 1028 & $\nu-\mathrm{C}=\mathrm{C}$ aromatic ring breathing & Stretching & & & $\mathrm{X}$ & & {$[43,47]$} \\
\hline 998 & $\nu$ - $\mathrm{CH}$ of benzene rings & Bending (deformation in the plane) & & & $\mathrm{X}$ & & [43] \\
\hline
\end{tabular}

a These peaks probably correspond also to the additive compounds. Lot of noise in area of $-\mathrm{CH}$ fingerprint. 


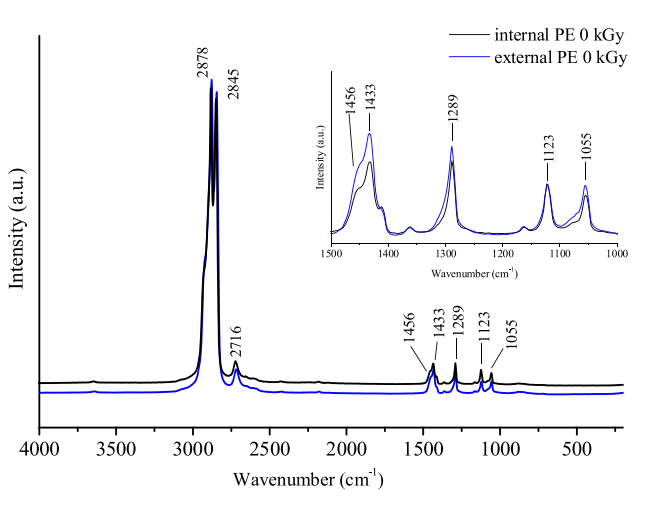

a)

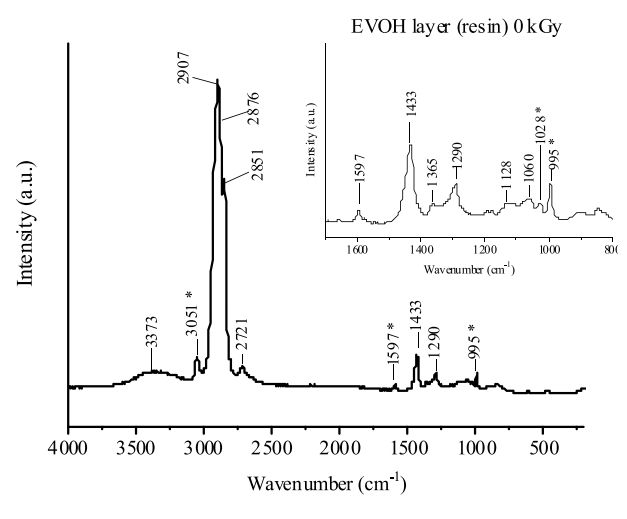

b)

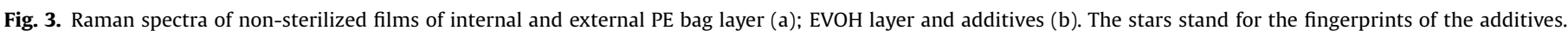

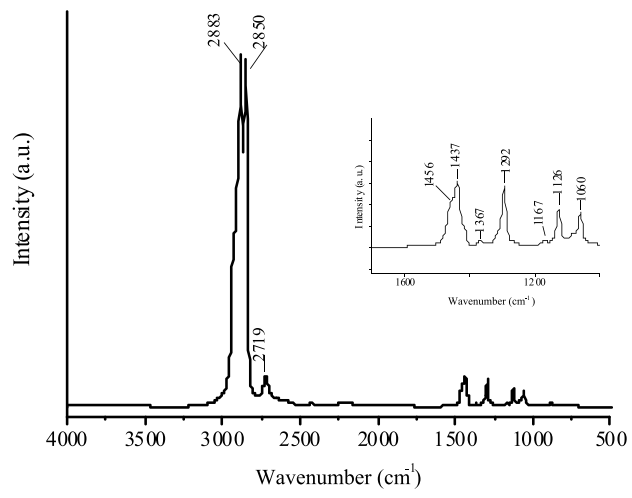

a)

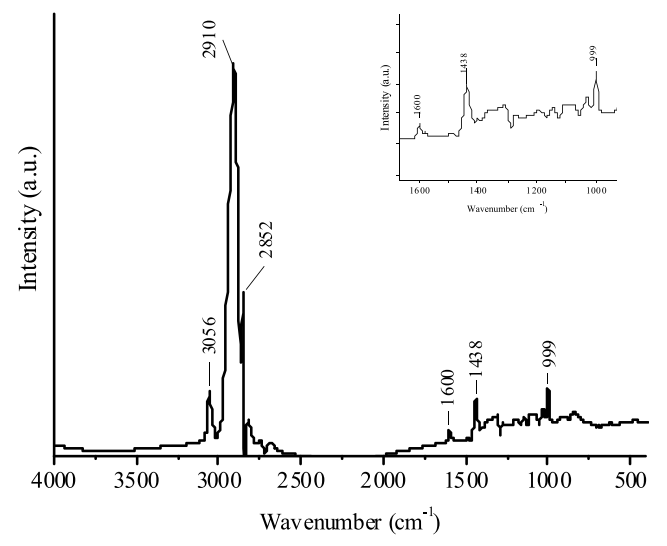

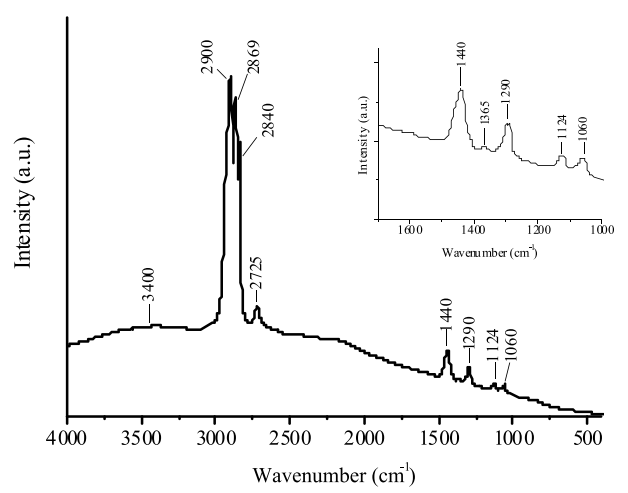

b)

c)

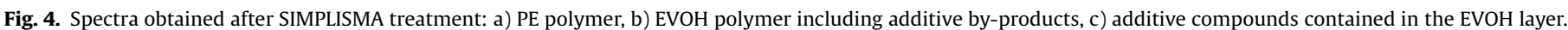

internal PE layer, as it is expected to get an identical spectrum for PE only slightly differing by their branching. The differentiation of both PE's by Simplisma is not possible due to the presence of the EVOH spectra in the data matrix inducing an important variance. The difference between the two PEs is then hidden by the variance EVOH|PE. Even by PCA, shown now in Fig. 1 SI, the differentiation between the two PEs is not possible. The concentration profiles of $\mathrm{PE}$ layer, EVOH layer and main additive compounds were obtained for each gamma-dose after processing data with SIMPLISMA
(Fig. 5). Because of focusing lens adjustment during Raman spectra acquisition the signal/noise ratio is too low for quantitative conclusions to be drawn, hence only trends observed in the concentration profiles are discussed.

The concentration profiles obtained for PE and EVOH are constant under gamma-irradiation, meaning that the degradation under gamma-irradiation is not significant enough to be detected by Raman spectroscopy. The fingerprints of PE and EVOH in Raman spectroscopy listed in Table 1 are not modified. The difference of 

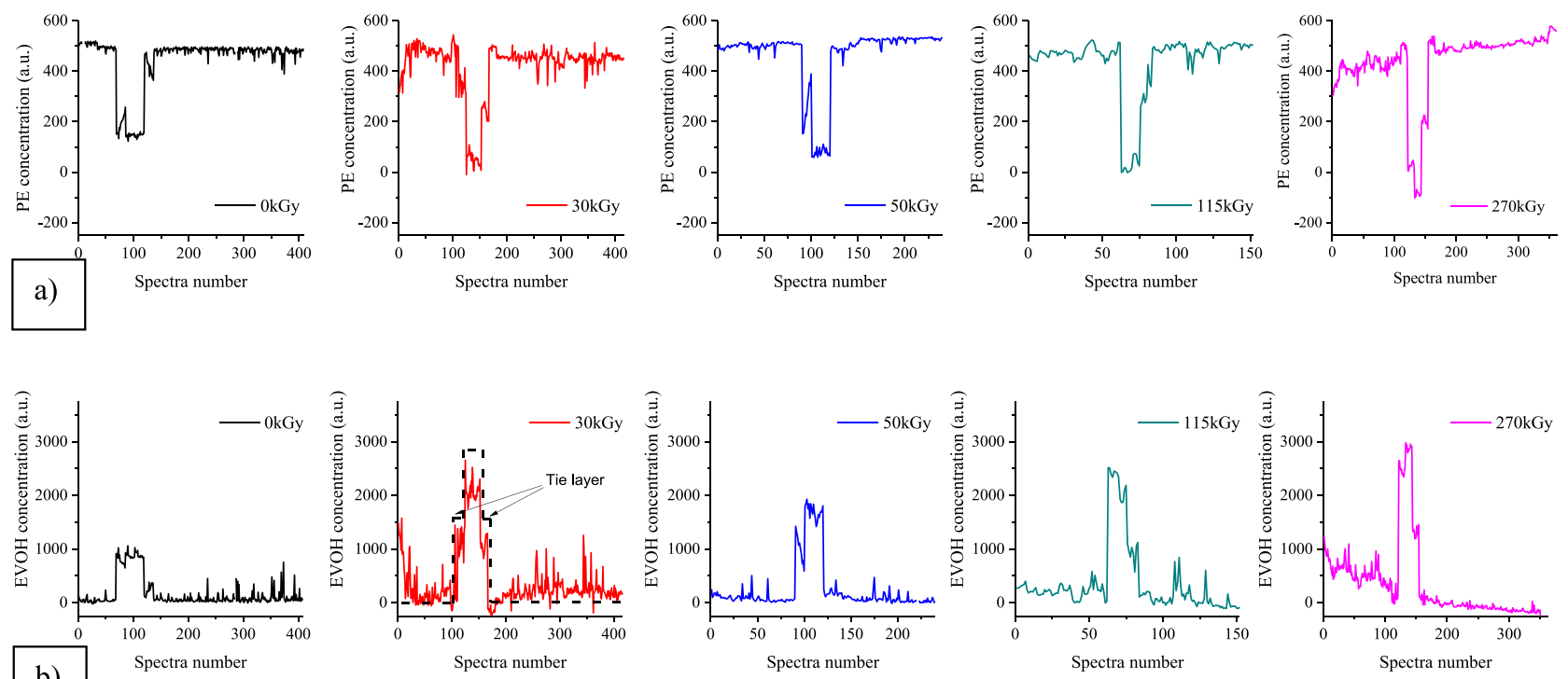

b)
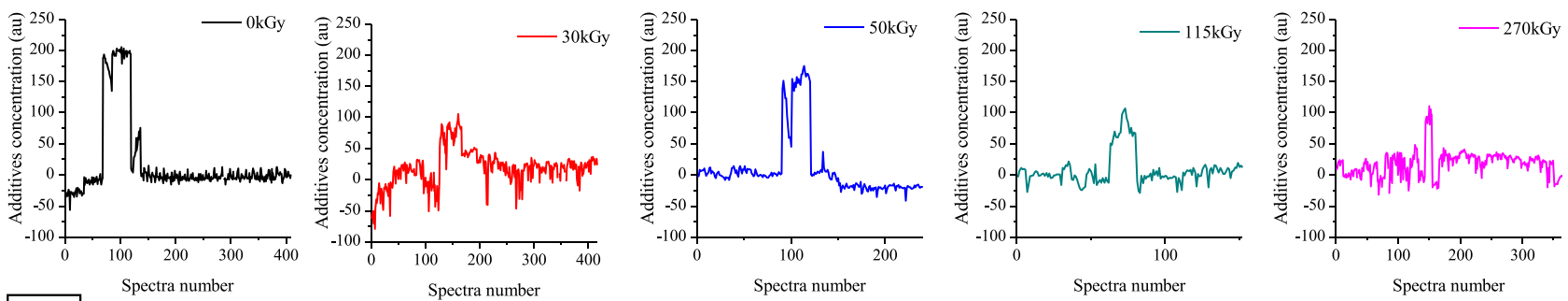

c)

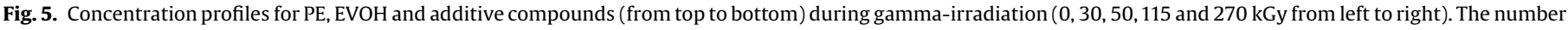

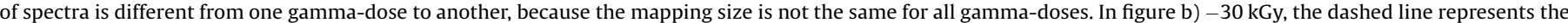

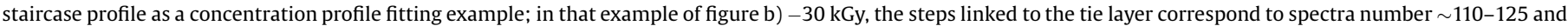
$\sim 150-165$.

the relative intensities and position of the bands observed between PE and EVOH spectra in Fig. 3 are conserved in the SIMPLISMA calculations.

The concentration profiles display an evolution of the additive compounds in the EVOH layer for an irradiation dose ranging from 0 to $270 \mathrm{kGy}$ (Fig. 5c)). This evolution is due to an intensity decrease of the fingerprint peaks of the additive compounds (3051, $1597,1028,995 \mathrm{~cm}^{-1}$ ). Other additive peaks of the additive package can be in common with the PE and EVOH peaks and cannot be thus monitored. Whatever the gamma-doses, the additive compounds are impacted while there is no linearity of the gamma-dose impact. The modification induced by gamma irradiation reveals in parallel a contribution of the fluorescence, which is visible through a drift of the baseline, meaning that species with high $\varepsilon$ (molar extinction coefficient) are generated. The fluorescence is due to several minor non-identified compounds in term on concentration which exhibit fluorescence. However, they are not concentrated enough to present detectable bands by Raman spectroscopy. Indeed, during gamma-irradiation, molecules are formed from the additive molecules [50], which can be at the origin of the fluorescence.

The concentration profile appearances for PE and EVOH are irregular whatever the dose, due to the tie layer used between these two layers. The use of tie layer is mandatory to glue incompatible materials such as PE and $\mathrm{EVOH}$. As the Raman resolution spot is $2.1 \mu \mathrm{m}$, the measurement in the interface tie layer/EVOH will result in combined spectrum signal of $\mathrm{PE}$ and spectrum signal of $\mathrm{EVOH}$. This accounts the appearance of a staircase curve in concentration profiles such as Fig. 5b) $-30 \mathrm{kGy}$. However, SIMPLISMA cannot provide a reconstructed signal for the tie layer as $\mathrm{C}-\mathrm{O}$ bonds are weakly observed in Raman, present in less than $1 \%$ of maleic moieties in recipe. The staircase curve signal width remains stable whatever the gamma irradiation dose applied from 30 to $270 \mathrm{kGy}$ letting us to presume the tie layer is not impacted during the irradiation process. The concentration profile in staircase curve varies as well from one sample to another showing tie layer thickness variations occurring during the manufacturing process without necessarily informing us about the interpenetration depth between the PE layer and the tie layer.

\section{Conclusion}

This work aims at revealing the impact of gamma-irradiation at different doses $(0,30,50,115$ and $270 \mathrm{kGy})$ on a multilayer PE-film ( $\mathrm{PE} / \mathrm{EVOH} / \mathrm{PE})$ observed by Raman spectroscopy. The large number of data and the weak intensity of changes concerning the peaks induced by the gamma irradiation could not give obvious interpretations with manual calculations leading us to use a curve resolution method (SIMPLISMA method).

Applying the SIMPLISMA method to PE-film Raman spectra enables us to reconstruct the pure spectra and the concentration profiles for each species: PE layer, EVOH layer and additive compounds. The constant concentration profiles for the PE and EVOH layers point out that these layers are not impacted by gamma-irradiation, while the variations of concentration profiles 
for the additive compounds in the EVOH layer show the impact of the gamma-irradiation.

The Raman PE and EVOH fingerprints are unchanged whatever the gamma irradiation dose, showing there is no detectable degradation of the $\mathrm{PE}$ or EVOH polymers. These observations mean that the integrity of polymer is preserved.

Additives compounds present in the EVOH layer are impacted by gamma-irradiation. Nevertheless, the exact chemical structure of the additive compounds cannot be determined, as only the more intense bands can be observed. It is interesting to note that the decrease in the content in additive compounds is regular for all gamma-doses. The new compounds that can be formed are extremely numerous. So if their structures are different we cannot detect them considering their low concentration. We can only argue that the additives are degraded into byproducts.

Although SIMPLISMA treatment cannot provide a reconstructed signal for the tie layer, the staircase curve signal remains stable within the gamma irradiation range applied $(0-270 \mathrm{kGy})$ allowing us presuming the tie layer is not impacted by the irradiation process.

The whole structure of the PE-film is thus not destroyed during the gamma irradiation as modifications took place at the additive package level without necessarily losing their functional attributes.

\section{Acknowledgements}

FG thanks Sartorius Stedim Biotech for PhD grant. ND and SRAM are thankful to AMU and CNRS for their support and to Sartorius Stedim Biotech for funding.

\section{References}

[1] A. Traboulsi, N. Dupuy, C. Rebufa, M. Sergent, Investigation of gamma radiation effect on the anion exchange resin Amberlite IRA-400 in hydroxide form by Fourier transformed infrared and $13 \mathrm{C}$ nuclear magnetic resonance spectroscopies, Anal. Chim. Acta 717 (2012) 110-121.

[2] A.E. Goulas, K.A. Riganakos, M.G. Kontominas, Effect of ionizing radiation on physicochemical and mechanical properties of commercial multilayer coextruded flexible plastics packaging materials, Radiat. Phys. Chem. 68 (2003) 865-872.

[3] M. Driffield, E. Bradley, L. Castle, Literature Review Analytical Screening and Chemical Migration Studies on Irradiated Food Packaging, (2009).

[4] J.C.M. Suarez, E.B. Mano, Characterization of degradation on gamma-irradiated recycled polyethylene blends by scanning electron microscopy, Polym. Degrad. Stab. 72 (2001) 217-221.

[5] M. Kurek, M. Ščetar, A. Voilley, K. Galić, F. Debeaufort, Barrier properties of chitosan coated polyethylene, J. Membr. Sci. 403-404 (2012) 162-168.

[6] K.J. Hemmerich, Medical Device and Diagnostic Industry Online:, (2000). http://www.mddionline.com/article/polymer-materials-selection-radiationsterilized-products.

[7] N.H. Stoffers, J.P.H. Linssen, R. Franz, F. Welle, Migration and sensory evaluation of irradiated polymers, Radiat. Phys. Chem. 71 (2004) 203-206.

[8] P.G. Demertzis, R. Franz, F. Welle, The effects of $\gamma$-irradiation on compositional changes in plastic packaging films, Packag. Technol. Sci. 12 (1999) 119-130.

[9] G. Audran, S. Dorey, N. Dupuy, F. Gaston, S.R.A. Marque, Degradation of $\gamma$-irradiated polyethylene-ethylene vinyl alcohol-polyethylene multilayer films: an ESR study, Polym. Degrad. Stab. 122 (2015) 169-179.

[10] A. Tidjani, Y. Watanabe, Gamma-oxidation of linear low density polyethylenes: the dose-rate effect of irradiation on chemical and physical modifications, J. Polym. Sci. Polym. Chem. 33 (1995) 1455-1460.

[11] J. Lacoste, D.J. Carlsson, Gamma-, photo-, and thermally-initiated oxidation of linear low density polyethylene: a quantitative comparison of oxidation products, J. Polym. Sci. Polym. Chem. 30 (1992) 493-500.

[12] J. Lacoste, D.J. Carlsson, S. Falicki, D.M. Wiles, Polyethylene hydroperoxide decomposition products, Polym. Degrad. Stab. 34 (1991) 309-323.

[13] A. Wesełucha-Birczynska, A. Fraczek-Szczypta, E. Długon, K. Paciorek, A. Bajowska, A. Koscielna, M. Błazewicz, Application of Raman spectroscopy to study of the polymer foams modified in the volume and on the surface by carbon nanotubes, Vib. Spectrosc. 72 (2014) 50-56.

[14] R.J. Meier, Studying the length of trans conformational sequences in polyethylene using Raman spectroscopy: a computational study, Polymer 43 (2002) 517-522.

[15] J.L. Koenig, Raman Scattering of Synthetic Polymers-A Review, Appl. Spectrosc. Review 4 (1971) 233-306.

[16] M. Pigeon, E.P. Prud'homme, M. Pezolet, Characterization of molecular orientation in polyethylene by Raman spectroscopy, Macromolecules 24 (1991) 5687-5694.

[17] M. Glotin, L. Mandelkern, A Raman spectroscopic study of the morphological structure of the polyethylenes, Colloid Polym. Sci. 260 (1982) 182-192.

[18] M. Tanaka, R.J. Young, Review polarised Raman spectroscopy for the study of molecular orientation distributions in polymers, J. Mater. Sci. 41 (2006) 963991.

[19] F. Rull, A.C. Prieto, J.M. Casado, F. Sobron, H.G.M. Edwards, Estimation of crystallinity in polyethylene by Raman spectroscopy, J. Raman Spectrosc. 24 (1993) 545-550.

[20] M.J. Gall, P.J. Hendra, C.J. Peacock, M.E.A. Cudby, H.A. Willis, Laser-Raman spectrum of polyethylene: part 1 . Structure analysis the polymer, Polymer 13 (1972) 104-108.

[21] M.J. Gall, P.J. Hendra, C.J. Peacock, M.E.A. Cudby, H.A. Willis, The laser-Raman spectrum of polyethylene: the assignment of the spectrum to fundamental modes of vibration, Spectrochim. Acta Part A: Mol. Spectrosc. 28A (1972) 1485-1496.

[22] T. Kida, Y. Hiejima, K.-H. Nitta, Rheo-optical Raman study of microscopic deformation in high-density polyethylene under hot drawing, Polym Test. 44 (2015) 30-36.

[23] R.P. Wool, R.S. Bretzlaff, Infrared and Raman spectroscopy of stressed polyethylene, J. Polym. Sci. Part B: Polym. Phys. 24 (1986) 1039-1066.

[24] J. Martin, M. Poncot, J.M. Hiver, P. Bourson, A. Dahoun, Real-time Raman spectroscopy measurments to study the uniaxial tension of isotactic polypropylene: a global overview of microstructural deformation mechanisms, J. Raman Spectrosc. 44 (2013) 776-784.

[25] T. Kida, T. Oku, Y. Hiejima, K. Nitta, Deformation mechanism of high-density polyethylene probed by in situ Raman spectroscopy, Polymer 58 (2015) 88-95.

[26] A.A. Abiona, A.G. Osinkolu, Gamma-irradiation induced property modification of polypropylene, Int. J. Phys. Sci. 5 (2010) 960-967.

[27] P. Taddei, S. Affatato, C. Fagnano, B. Bordini, A. Tinti, A. Toni, Vibrational spectroscopy of ultra-high molecular weight polyethylene hip prostheses: influence of the sterilisation method on crystallinity and surface oxidation, J. Mol. Struct. 613 (2002) 121-129.

[28] B. Vajna, B. Bodzay, A. Toldy, I. Farkas, T. Igricz, G. Marosi, Analysis of car shredder polymer waste with Raman mapping and chemometrics, Express Polym. Lett. 6 (2012) 107-119.

[29] W. Windig, J. Guilment, Interactive self-modeling mixture analysis, Anal. Chem. 63 (1991) 1425-1432.

[30] V. Vacque, N. Dupuy, B. Sombret, J.P. Huvenne, P. Legrand, Self-modeling analysis applied to FT-Raman spectral data of hydrogen peroxyde activation by nitriles, Appl. Spectrosc. 51 (1997) 407-415.

[31] Guide to irradiation and sterilization validation of single-use bioprocess systems. BioProcess International. May 2008 Supplement: 10-22.

[32] D.H. Jeon, G.Y. Park, I.S. Kwak, K.H. Lee, H.J. Park, Antioxidants and their migration into food simulants on irradiated LLDPE film, LWT 40 (2007) 151 156.

[33] F. Bourges, G. Bureau, J. Dumonceau, B. Pascat, Effects of electron beam irradiation on antioxidants in commercial polyolefins: determination and quantification of products formed, Packag. Technol. Sci. 5 (1992) 205-209.

[34] J. Pospisil, Chemical and photochemical behaviour of phenolic antioxidants in polymer stabilization-a state of the art report. Part I, Polym. Degrad. Stab. 40 (1993) 217-232.

[35] W. Windig, D.A. Stephenson, Self-modeling mixture analysis of secondderivative near-infrared spectral data using the SIMPLISMA approach, Anal. Chem. 64 (1992) 2735-2742.

[36] W. Windig, The use of second-derivative spectra for pure-variable based selfmodeling mixture analysis techniques, Chemom. Intell. Lab. 23 (1994) 71-86

[37] W. Windig, Spectral data files for self-modeling curve resolution with examples using the SIMPLISMA approach, Chemom. Intell. Lab. 36 (1997) 3-16.

[38] P.J. Gemperline, Mixture analysis using factor analysis I: calibration and quantitation, J. Chemom. 3 (1989) 549-568.

[39] J.C. Hamilton, P.J. Gemperline, Mixture analysis using factor analysis II: selfmodeling curve resolution, J. Chemom. 4 (1990) 1-13.

[40] W. Windig, S. Markel, Simple-to-use interactive self-modeling mixture analysis of FTIR microscopy data, J. Mol. Struct. 292 (1993) 161-170.

[41] L.A. Currie, Metrological measurement accuracy: discussion of "measurement error models" by Leon Jay Gleser, Chemom. Intell. Lab. 10 (1991) 59-67.

[42] O. Abbas, N. Dupuy, C. Rebufa, L. Vrielynck, J. Kister, A. Permanyer, Prediction of source rock origin by chemometric analysis of Fourier transform infraredattenuated total reflectance spectra of oil petroleum: evaluation of aliphatic and aromatic fractions by self-modeling mixture analysis, Appl. Spectrosc. 60 (2006) 304-314.

[43] G. Socrates. Infrared and Raman characteristic group frequencies, John Wiley \& Sons, 3rd Edition. p51-54; p70-75; p159.

[44] M. Kim, J. Noh, H. Chung, Comparison of near-infrared and Raman spectroscopy for the determination of the density of polyethylene pellets, Anal. Chim. Acta 632 (2009) 122-127. 
[45] W. Lin, M. Cossar, V. Dang, J. The, The application of Raman spectroscopy to three-phase characterization of polyethylene crystallinity, J. Polym. Test. 26 (2007) 814-821.

[46] J. Kim, Y. Kim, H. Chung, Direct on-line Raman measurement of flying solid samples: determination of polyethylene pellet density, Talanta 83 (2011) 879884.

[47] J.K.F. Tait, H.G.M. Edwards, D.W. Farwell, J. Yarwood, Fourier transform Raman spectroscopic examination of two amine-based epoxy resin crosslinking agents, Spectrochim. Acta Part A: Mol. Spectrosc. 51 (1995) 2101-2106.
[48] X.M. Sui, C.L. Shao, Y.C. Liu, White-light emission of polyvinyl alcohol/ZnO hybrid nanofibers prepared by electrospinning, Appl. Phys. Lett. 87 (2005) $113-115$.

[49] T.F. Cooney, L. Wang S.K. Sharma, R.W Gauldie, A.J. Montana, Raman spectra study of solid and dissolved poly(vinyl alcohol) and ethylene-vinyl alcohol copolymer, J. Polym. Sci. Polym. Phys. 32 (1994) 1163-1174.

[50] I. Vulic, G. Vitarelli, J.M. Zenner, Structure-property relationships: phenolic antioxidants with high efficiency and low colour contribution, Polym. Degrad. Stab. 78 (2002) 27-34. 